\title{
AC Impedance Spectroscopy of Lithium-Ion Secondary Cell Exposed to Elevated Temperature
}

\author{
Tomomi Harada, ${ }^{\mathrm{a}}$ Jun-ichi Tanaka, ${ }^{\mathrm{a}}$ Akira Nakazawa, ${ }^{\mathrm{a}}$ Minoru Umeda, ${ }^{\mathrm{a}, *}$ \\ and Yoshitsugu SonE
}

\author{
aNagaoka University of Technology (1603-1 Kamitomioka, Nagaoka, Niigata 940-2188, Japan) \\ bJapan Aerospace Exploration Agency (7-44-1 Jindaiji Higashimachi, Chofu, Tokyo 182-8522, Japan)
}

Received December 4, 2009 ; Accepted January 19, 2010

\begin{abstract}
An investigation of the thermal deterioration characteristics of a lithium-ion secondary cell is inevitable for in utilization for electric vehicles. An accelerating rate calorimeter study revealed that the thermal runaway of the cell occurs over $130{ }^{\circ} \mathrm{C}$. In the present study, the thermal deterioration characteristics of a lithium-ion secondary cell during a $100^{\circ} \mathrm{C}$ storage have been investigated by varying the state of charge (SOC). The measured impedance spectra have been analyzed based on an equivalent circuit, which consists of resistances of the anode and cathode (R1 and R2). Based on the analyses, the increasing rates of R1 and R2 can be defined. The rate of R1 is lower than that of R2 for an SOC of 87\%; conversely, that of R1 is greater than that of R2 for SOCs of 66 and $44 \%$. Moreover, the increasing rates of both R1 and R2 are found to become significant when the magnitude of the SOC increases. The increasing rate of R2 more strongly depends on the SOC than that of R1. These results mean that the cathode material is thermally unstable when the extent of lithium deterioration is high.
\end{abstract}

Key Words : Lithium-ion Secondary Cell, Accelerating Rate Calorimeter, Heat Hazard, Impedance Spectroscopy

\section{Introduction}

Lithium-ion secondary cells are utilized as power sources in many portable electronic devices, because of their high energy density, small size and light weight.1) Currently, the cells are being used for electric vehicles, ${ }^{2)}$ which leads to the fact that the cells will be exposed to more severe operating conditions. Especially, the heat hazard should be taken into account, because the lithium-ion secondary cells are known to deteriorate at a high rate at a temperature around $60^{\circ} \mathrm{C} .{ }^{3,4)}$

To develop a quick and safe heat hazard test for the lithium-ion secondary cells, the use of an accelerating rate calorimeter (ARC) is considered to be effective. ${ }^{5)} \mathrm{We}$ have investigated the thermal runaway characteristics and stability of lithium-ion secondary cells over $100^{\circ} \mathrm{C}$ by employing the ARC. ${ }^{6}$ In this study, we focused our attention on the thermal hazard of the lithium-ion secondary cell at $\sim 100{ }^{\circ} \mathrm{C}$, and investigated its deterioration behavior by ac impedance spectroscopy.

\section{Experimental}

A commercially available 18650-type lithium-ion secondary cell, which has a rated capacity of $2550 \mathrm{mAh}$ and average discharge voltage of $3.7 \mathrm{~V}$, was used for the $100{ }^{\circ} \mathrm{C}$ storage test at several levels of "state of charge (SOC)". The SOC level of the cell was set at 44, 66, and $87 \%$ by a charge/discharge procedure, and then placed in the ARC (Columbia Scientifics, Inc.). The temperature of the ARC chamber was increased so that the surface temperature of the cell was fixed at $100^{\circ} \mathrm{C}$ using a thermocouple attached to the cell. First, the open circuit voltage $(\mathrm{OCV})$ of the cell was continuously measured by a voltmeter (HE-104A, Hokuto Denko) until the cell voltage decreased to $2 \mathrm{~V}$.

Based on this test, a cell deterioration time was realized for each SOC sample. Three samples with the same SOC were then conditioned and put into the oven chamber (HIFREX FL414 PH, ETAC) stabilized at $100^{\circ} \mathrm{C}$. By changing the storage period, the three samples were taken out and cooled over night. The ac impedance measurement was performed at the $\mathrm{OCV}$ of the cell at $25^{\circ} \mathrm{C}$ using a battery measurement system (As-510-B60, NF Corp.) in combination with a frequency response analyzer (FRA5014, NF Corp.). The frequency range was 10 $\mathrm{kHz}-10 \mathrm{mHz}$, and the amplitude of the voltage was less than $5 \mathrm{mV}$.

The obtained spectra were evaluated by fitting the electrode response to an equivalent circuit using ZView software (Scribner Associates). We employed the equivalent circuit shown in Fig. 1, which is commonly used to simulate the impedance response of lithium-ion secondary cells. ${ }^{7)}$ In the circuit, the element Rs represents the ohmic resistance of the cell, and we ascribed R1 to the resistance of the cell reaction at the anode and $\mathrm{R} 2$ to that at the cathode, while CPE1 and CPE2, respectively, denote the constant phase elements of the anode and

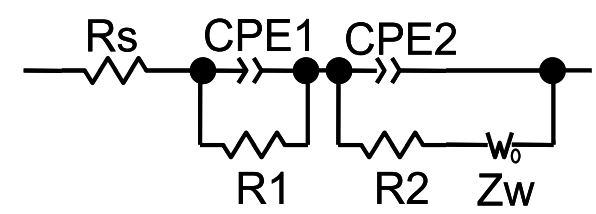

Fig. 1 Equivalent circuit used for impedance fitting. 
cathode. .,9) $^{\text {T) }}$

To measure the capacity loss of the lithium-ion secondary cell after the $100{ }^{\circ} \mathrm{C}$ storage test, the cell was charged and discharged in constant current (CC) and constant voltage $(\mathrm{CV})$ modes at $25^{\circ} \mathrm{C}$ using a battery tester (PFX2001, KIKUSUI). The charging of the cell was performed using a $\mathrm{CC}$ protocol to the upper potential of $4.2 \mathrm{~V}$ then using the $\mathrm{CV}$ protocol until the current dropped to less than $0.05 \mathrm{C}$, and the discharge to the lower cutoff potential of $2.75 \mathrm{~V}$ using the $\mathrm{CC}$ protocol.

\section{Results and Discussion}

Figure 2 shows the OCV dependence on the cell storage time at $100{ }^{\circ} \mathrm{C}$ as a function of the SOC. It is known from this figure that the OCV gradually decreases, and then suddenly goes down after $144 \mathrm{~h}$ of storage for $\mathrm{SOC}=44 \%, 62 \mathrm{~h}$ for $\mathrm{SOC}=66 \%$, and $18 \mathrm{~h}$ for $\mathrm{SOC}=$ $87 \%$. The charge-discharge capacities of the samples were measured just before and after the significant OCV drop. The magnitude of the capacity just before the OCV drop was found to be greater than $90 \%$ for the same sample prior to the heat treatment. However, after the OCV drop, the capacity was found to be zero. These results indicate that the OCV deterioration is not caused by the decomposition of the electrode materials, but by the safety function of the device, i.e., the Current Interrupt Device (CID), built into the cell. ${ }^{10,11)}$

Based on the results seen in Fig. 2, the $100{ }^{\circ} \mathrm{C}$ heattreated cells were removed from the oven chamber after 2.5, 5, and $7.5 \mathrm{~h}$ for $\mathrm{SOC}=87 \%$, after 24 and $48 \mathrm{~h}$ for $\mathrm{SOC}=66 \%$, and after 48,72 , and $96 \mathrm{~h}$ for $\mathrm{SOC}=44 \%$. These cells were then stored in a $25^{\circ} \mathrm{C}$ chamber (HP12025, ISUZU Corp.) over night to stabilize the samples for the impedance spectrum measurement.

Figure 3 shows the impedance spectra of the $\mathrm{SOC}=$ $87 \%$ cells before and after the $100{ }^{\circ} \mathrm{C}$ storage test. Each spectrum consists of two semicircles, and the magnitudes of the circles become larger when the storage time becomes longer. It is reported that semicircle 1, which

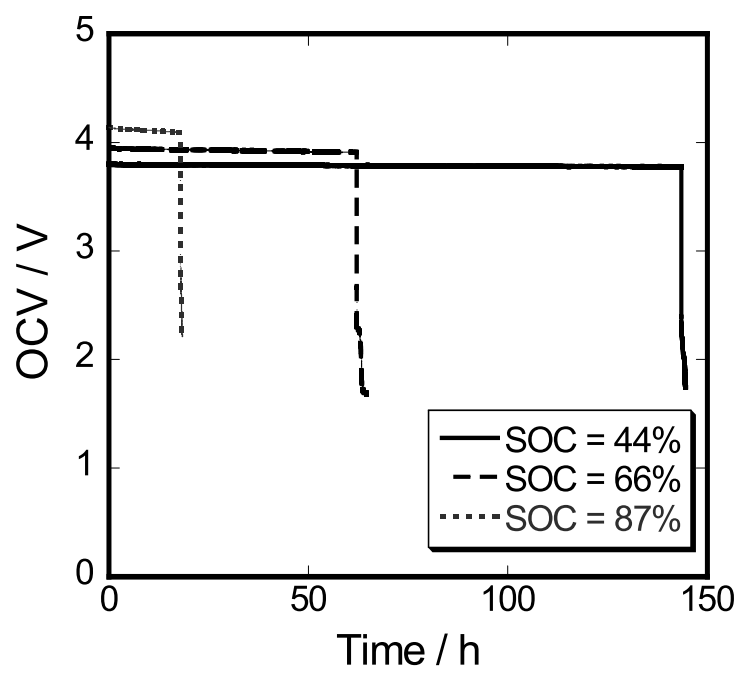

Fig. 2 Time dependent OCV change of the cell stored at $100{ }^{\circ} \mathrm{C}$. appeared in the high-frequency region, and the semicircle 2 , in the middle-frequency region, reflect the characteristics of the anode and cathode, respectively. ${ }^{8,9)}$ Therefore, the result that the semicircle diameter increases with the storage time is attributed to a deterioration generated by the heat.

The impedance spectra seen in Fig. 3 were analyzed by the curve fitting based on an equivalent circuit, in which Rs, R1 and R2 denote the resistances of the solution, anode and cathode, respectively. The analyzed results are shown in Fig. 4. In the figure, each resistance becomes greater according to the increase in the storage time. Thus the observed increase in each resistance is thought to be based on deterioration of the electrode active materials, solid electrolyte interface (SEI), and binder resin. ${ }^{12,13)}$

It is also known from Fig. 4 that the resistances linearly increase in proportion to the storage time. Thus, we define the increased rate from the slope of the plots. Figure 5 summarizes the results versus the SOC. First, the increasing rates of $\mathrm{R} 1$ and $\mathrm{R} 2$ are compared. The rate of $\mathrm{R} 1$ is known to be lower than that of $\mathrm{R} 2$ for $\mathrm{SOC}=87 \%$; however, that of $\mathrm{R} 1$ is greater than that of $\mathrm{R} 2$ for $\mathrm{SOC}=66$ and $44 \%$. Next, the SOC dependence of both increased rates is assessed. Consequently, the increased rates of both $\mathrm{R} 1$ and $\mathrm{R} 2$ become greater with an increase in the magnitude of the SOC. The increasing rate of $\mathrm{R} 2$ more strongly depends on the SOC than that of R1. These results strongly suggest that the cathode material is thermally unstable when the extent of lithium deterioration is high. It is reported that the thermal runaway generally starts at the anode, and then the cathode becomes involved. ${ }^{14)}$ However, the results seen in Fig. 5, which are different from the reported thermal runaway characteristics, are considered to be attributed to another deterioration mode at that temperature. ${ }^{15)}$

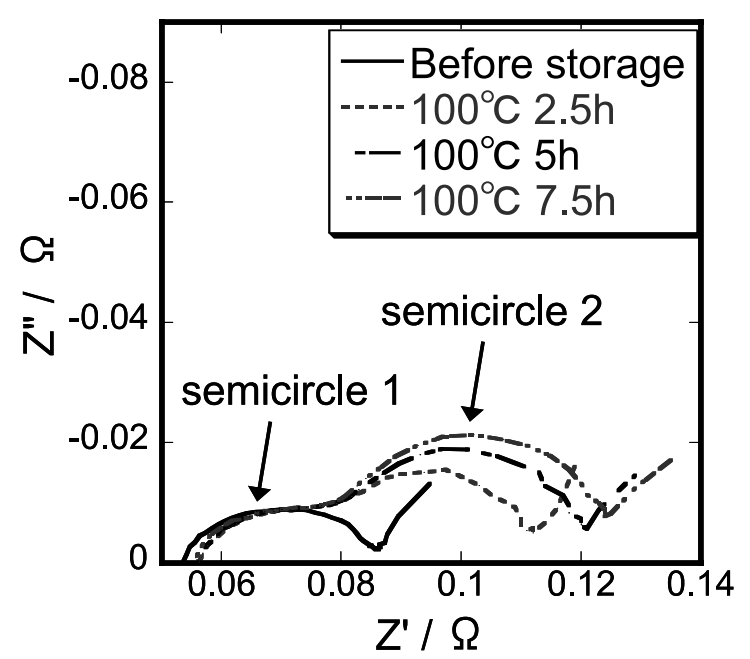

Fig. 3 Impedance spectra of lithium-ion secondary cell $(\mathrm{SOC}=87 \%)$ measured at $25^{\circ} \mathrm{C}$ before and after the $100{ }^{\circ} \mathrm{C}$ storage. 


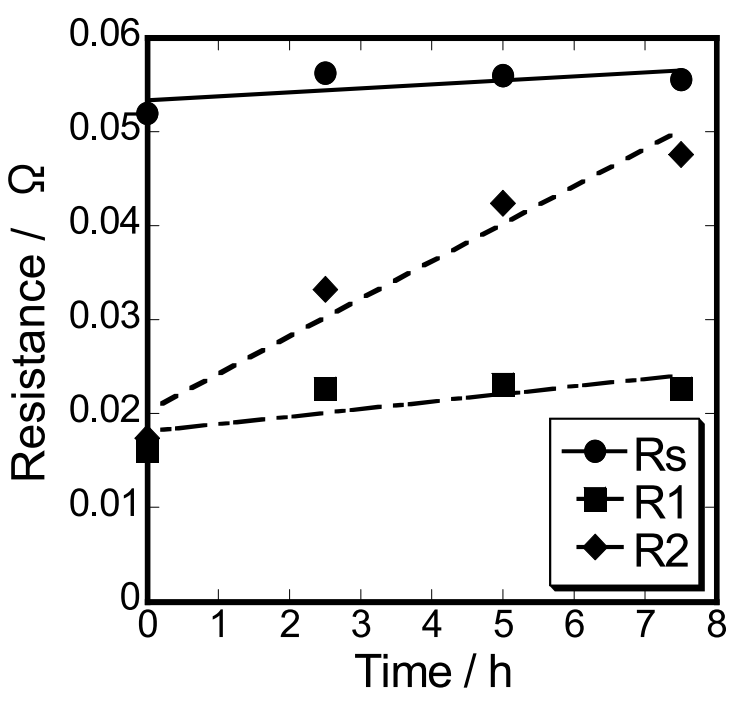

Fig. 4 Storage time dependence of the increasing rate of resistance $(\mathrm{SOC}=87 \%)$. The data are taken from Fig. 3 .

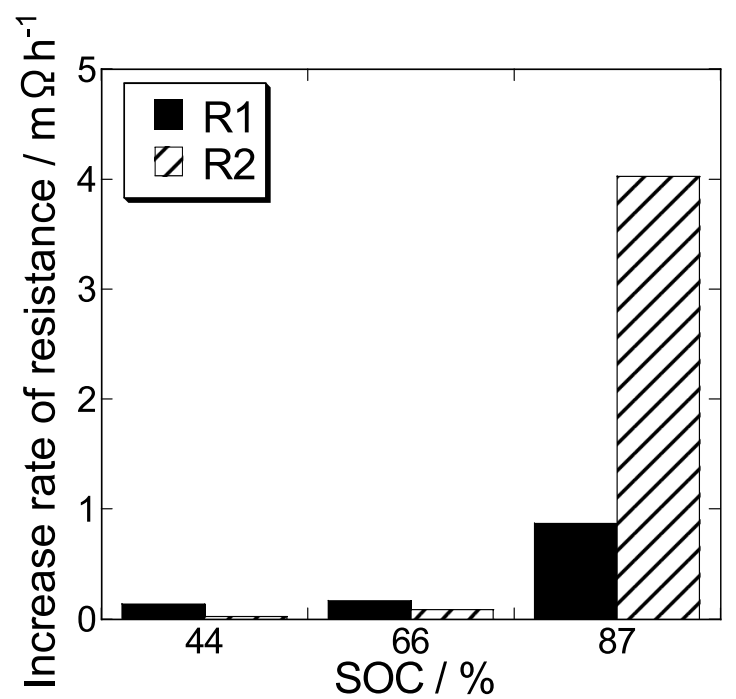

Fig. 5 Increasing rate of resistances during $100{ }^{\circ} \mathrm{C}$ cell storage.

\section{Conclusion}

In the present study, the $100{ }^{\circ} \mathrm{C}$ storage test of the lithium-ion secondary cell was conducted by varying its SOC. The results are summarized as follows.

During the $100{ }^{\circ} \mathrm{C}$ storage, the OCV of the cell sharply decreased after $144,62,18 \mathrm{~h}$ for $\mathrm{SOC}=44,66,87 \%$, respectively. The charge/discharge capacity of each sample just before the sudden OCV decrease was about $90 \%$ of the same sample prior to the storage. This implies that the safety function takes place when the battery is stored at $100^{\circ} \mathrm{C}$.

Based on the ac impedance analyses, the increasing rates of $\mathrm{R} 1$ and $\mathrm{R} 2$ can be defined. The rate of $\mathrm{R} 1$ was known to be lower than that of R2 for SOC $=87 \%$; conversely, that of $\mathrm{R} 1$ was greater than that of $\mathrm{R} 2$ for $\mathrm{SOC}=66$ and $44 \%$. Next, the increasing rates of both R1 and R2 were found to increase when the magnitude of SOC increased. The increasing rate of R2 more strongly depends on the SOC than that of $\mathrm{R} 1$. These results strongly suggest that the cathode material is thermally unstable when the extent of lithium deterioration is high.

\section{Acknowledgement}

This work was supported by the "Li-EAD project" program from the New Energy and Technology Development Organization (NEDO), Japan.

\section{References}

1) K. Takeno, M. Ichimura, K. Takano, and J. Yamaki, J. Power Sources, 142, 298 (2005).

2) N. Sato, J. Power Sources, 99, 70 (2001).

3) J. Yamaki, Netsu Sokutei, 30, 3 (2003) [in Japanese].

4) Y. Saito and M. K. Rahman, The 72th Annual Meeting of the Electrochemical Society of Japan, Abstr., p.275 (2005).

5) I. Uchida, H. Ishikawa, M. Mohamedi, and M. Umeda, J. Power Sources, 119-121, 821 (2003).

6) T. Harada, J. Tanaka, A. Nakazawa, and M. Umeda, manuscript in preparation.

7) M. Mohamedi, H. Ishikawa, and I. Uchida, J. Appl. Electrochem., 34, 1103 (2004).

8) K. Takeno, M. Ichimura, K. Takeno, J. Yamaki, and S. Okada, J. Power Sources, 128, 67 (2004).

9) H. Kondo, Y. Takeuchi, T. Sasaki, S. Kawauchi, Y. Itou, O, Hiruta, C. Okuda, M. Yonemura, T. Kamiyama, and Y. Ukyo, J. Power Sources, 174, 1131 (2007).

10) H. Lee, S. Kim, J. Jeon, and J. Cho, J. Power Sources, 173, 972 (2007).

11) G. Venugopal, J. Power Sources, 101, 231 (2001).

12) M. S. Wu and P. C. J. Chiang, Electrochim. Acta, 52, 3719 (2007).

13) Y. Sone, X. Liu, T. Inoue, X. Wang, and S. Kuwajima, Electrochemistry, 71, 542 (2003) [in Japanese].

14) D. D. Mackneil and J. R. Dahn, J. Electrochem. Soc., 148, A1205 (2001).

15) P. L. Moss, G. Au, E. J. Plichta, and J. P. Zheng, J. Power Sources, 189, 66 (2009). 